REVIEW

\title{
A Review of Literature in Applied Five Factor Model of Personality among Staff at Workplace
}

\author{
Aida Merhad ${ }^{1 *}$ \\ ${ }^{1}$ University Putra Malaysia (UPM) \\ *Corresponding author: Aida Merhad: mehrad.aida@gmail.com
}

\section{OPEN - ACCESS}

Citation: Merhad A. (2020) A Review of Literature in Applied Five Factor Model of Personality among Staff at Workplace. Open Science Journal 5(3)

Received: $9^{\text {th }}$ April 2020

Accepted: $27^{\text {th }}$ July 2020

Published: $17^{\text {th }}$ August 2020

Copyright: (c) 2020 This is an open access article under the terms of the Creative Commons Attribution License, which permits unrestricted use, distribution, and reproduction in any medium, provided the original author and source are credited.

Funding: The author(s) received no specific funding for this work

Competing Interests: The author has declared that no competing interests exists.

\begin{abstract}
:
Staff feeling and performance at the workplace and obtaining a high level of outcomes drive from various factors; in truth, the human being is complicated and there are numerous internal and external factors that have an impact on it. Personality determined as one of these main internal factors that introduced individuals at their personal and social life; furthermore, recognizing its deep definition and effect on the approach and accomplishment of staff stays valuable and essential. Personality consists of five main factors: neuroticism, extraversion, openness, agreeableness, and conscientiousness that each person based on these factors illustrates dissimilar behavior and response. Additionally, the person introduced or well-known via these factors. Incidentally, the present literature review surveys five personality factors amongst staff in the context of the Five Factor Model and analyzes staff performance and behavior at the workplace. Overall, the study emphasized the role of managers, leaders, supervisors, etc. at the workplace to identify and evaluate staff personality, because by recognizing staff personality managers can offer a suitable solution to coping and solving any type of conflict or issue.
\end{abstract}

Keywords: Agreeableness, Conscientiousness, Extraversion, Five Factor Model, Neuroticism, Openness, Personality, Staff, Workplace 


\section{Introduction}

Personality assumed as one of the considerable and internal factors that should care more from staff and workplaces (managers, leaders, supervisors, etc.) because be able to change the level of attitudes and performance of staff at work (Furnham, Petrides, Jackson, \& Cotter, 2002). Personality comprised five principle factors; in truth, these factors assumed as inner motivators that impact feelings of staff (Yeop Yunus \& Ishak, 2012). These factors also nominated as Big Five Personality Factors that have direct relations with the self and the inner world (Wadhwa, Verghese, \& Wadhwa., 2011). Indeed, these factors are symbolic aspects of the job and have the main role in emotion, also create several attitudes among staff. These factors similarly evaluate the structures of performance, relation, interest, motivation, duty, organizational consequences, level of exhaustion, and stress (Ali \& Akhter, 2009). This literature review considered the Big Five Personality Factors in the context of the Five Factor Model among staff at the workplace that are explained follows, comprehensively.

\section{Personality of staff: performance and behavior}

\section{What is personality?}

Personality is a combination of distinct characteristics, schemas, emotions, opinions, and feelings that segregated an individual from others. This inner factor originates from within the individual and remains throughout life. Personality as well refers to different characteristics of a human being that becomes a unique individual in society (Lounsbury, Hutchens, \& Loveland, 2005; Srivastava, 2010). Certainly, this factor has a widespread role in behaviors and reactions that appear in society and formed organizational features at the workplace (Barkhuizen, Swanepoel, \& Ermakova, 2012; Tella, Ayeni, \& Popoola, 2007). Based on previous investigations such as Judge, Klinger, Simon, and Yang (2008) that explained organizational behaviors predicted by big five personality factors which included staff performance, motivation, attitudes toward work, leadership, power and politics, stress and anxiety, team working, amount of outcomes, irregular reactions, fate, and conflict at the workplace. Truly, personality impacts on these behaviors and has a noticeable role among staff in their work-life and creates various results. For the most part, personality assumed as a typical method in which staff responds to conditions at work (Poropat, 2009). In a similar vein, Kafetsios, and Zampetakis (2008) stated personality impacts on various factors such as basic human needs. The factors of personality associated with the ability of behaviors and activities similarly influence on social reactions. Correspondingly, Ayan and Kocacik (2010) described that personality is one of the most important factors to rise or reduce positive feelings and satisfaction toward a job at the workplace.

Certainly, personality defined as a stability among individuals that impact their idea, accomplishment, behavior, and approach. In other words, personality determined as monitoring of individual mood, beliefs, attitude, and considerate (Clark, Kotchen, \& Moore, 2003; Bauger, 2011). Similarly, Eley, Cloninger, Walters, Laurence, Synnott, and Wilkinson (2013) characterized personality as a collection of emotions, attitudes, and manners. As a matter of fact, personality is a set of emotional reactions that demonstrates ways of relating to others. In 
Addition, this factor assumed as a mask that individuals wear and based on it, have a relationship with others (Hazrati, Zabihi, \& Mehdizadeh, 2013). Well, personality in the social psychology context is identified as the most important factor for analyzing individuals' behaviors and reactions in a different situation. It shows individuals' performance based on their living situation (Franzoi, 2006).

General, the personality included five main factors: neuroticism, extraversion, openness, agreeableness, and conscientiousness (Fayombo, 2010). These factors are attributed to individuals' behaviors that appear in society (Althoff, 2010). The factors of personality estimated by self-report or peer reports that connect with social behaviors (Saklofske, Austin, Rohr, \& Andrews, 2007). In an investigation, Yap, Anusic, and Lucas (2012) explained that each of these five factors has consequences on feelings, emotions, and behaviors of individuals in their personal and social life independently. According to Gurven, Rueden, Massenkoff, Kaplan, and Lero Vie (2013) personality comprises five main factors that considered as a core basic within individual characteristics. These factors are separately explained below.

\section{Big five personality factors}

\section{Neuroticism}

As mentioned above, personality comprised five main factors that each of them has various influences on individual behavior, performance, reaction, etc. for instance Neuroticism assumed as a fundamental personality factor that appears as a negative mood for a long time. This factor creates some bad experiences such as stress, anger, and anxiety mood among individuals with the work environment (Saklofske et al., 2007). Regarding Fayombo (2010), neuroticism as a negative factor leads to any undesirable reactions and behaviors such as anger and depress mood among individuals. Truly, this factor of personality generates unrespectable conditions for individuals and decreases the amount of their presence in society because of the dissatisfaction of most of the cases.

\section{Openness}

In contrast to neuroticism, Openness refers to independent imaginations that grow by individuals in their social life. In other words, it is a kind of ingenuity and intellectual interest among individuals. This factor of personality is described in various definitions but in some cases, openness is characterized as wisdom. As well, openness distinguishes as released emotion, thought, activity, and experience that illustrate the amount of mental creativity and performance (Poropat, 2009). Corresponding to Fayombo (2010) openness assumed as an independence factor, and it does not have any relationship with neuroticism. This factor is so valuable for the creativity of staff which has a direct association with their feeling and performance (Barkhuizen et al., 2012). The openness staff have a positive view of their job and show happiness and satisfaction about their work and its environment (Naz, Rehman, \& Saqib, 2013).

Agreeableness

Agreeableness as another personality factor refers to collaboration, friendly, and sociability behavior with co-workers at the work (Bauger, 2011; Yap et al., 
2012). Agreeableness has a significant role amongst staff and displays positive behavior such as honesty and truthfulness in the work environment (Lounsbury et al., 2005; McCrae, 2010; Gurven et al., 2013). Besides, agreeableness is written off as a positive factor that elevations the amount of staff performance and has a relationship with happiness and satisfaction (Barkhuizen et al., 2012; Naz et al., 2013). In a study, Mikolajczak, Luminet, Leroy, and Roy (2007) pointed out agreeableness is the personal capability of working with others in a long time. Certainly, individuals with this characteristic presented interest in integrating into social conditions and support others in society. Into the bargain, agreeableness has a positive relationship with the emotions of individuals.

\section{Extraversion}

Likewise, Extraversion as another factor well-defined as sociability, energetic, and talkative characteristic that individuals endeavor to demonstrate to them in a social environment (Gurven et al., 2013). Extrovert individuals have optimistic views about everything that occurs in personal and social life and they develop positive energy in a social place. Truly, staff with this personality cope with difficulties and believe these unpleasant happens will be solved without a doubt (Saklofske et al., 2007; McCrae, 2010). Additionally, extraversion supports behavioral reactions that appear in the work-life (Voon, Lo, Ngui, \& Ayob, 2011). To sum up, extraversion is present in most of personality inventory analysis because it can predict social reactions and has an association with industrial behaviors at the organization (Barkhuizen et al., 2012). In consequence, this factor of personality assumed as a positive motivator in which appears as a real feeling and acceptable organizational behavior at work (Cooper, Carpenter, Reiner, \& McCord, 2014)

\section{Conscientiousness}

Conscientiousness acknowledged as a trend to become self-discipline in private and social life. Truthfully, individuals with this type of personality can manage their affairs straightforwardly (Bauger, 2011; Yap et al., 2012). This factor determined as combined with a set of accuracy and responsibility toward work (Reid-Cunningham, 2008). In the same vein, Fayombo (2010) explained conscientiousness can control every plan and project; correspondingly, this factor assumed as a solvable factor for complications that occur in private and social life. Conscientiousness has a positive impact on hard-working and reliability (Eley et al., 2013).

Concerning the definitions of big five personality factors in this literature review, in the next section, the researcher focused on the Five Factor Model, generally.

\section{The five factor model}

Concurring to the role of personality factors, the Five Factor Model described the presence and influence of these five factors on different behaviors. Furthermore, this model defined the big five personality factors (Neuroticism, extraversion, openness, agreeableness, and conscientiousness), remarkably. This model proposed by Costa and McCrae (1992) that exemplified five factors of 
personality which separately affected different population such as staff. It similarly expounded the association between the various factors of personality with different behaviors and reactions. The Five Factor Model developed and elaborated over the last five decades in diverse cultures and the researchers are the strongest supporters of this comprehensive model (Rothmann \& Coetzer, 2003).

The big five personality factors present a framework for staff to represent a variety of behaviors and reactions in the social environment (Tan \& Waheed, 2011). To tell the truth, big five personality factors affect human behavior and change individuals' socio-cognitive, reactions, attitudes, concepts, and feelings at work (McCrae, 2010). The Five Factor Model accurately emphasized the critical role of the five personality factors as an internal motivator on basic human needs (Althoff, 2010; Gurven et al., 2013). The five factors that have been mentioned before; likewise, are considered as staff patterns that affect social behavior (Petrides, Pita, \& Kokkinaki, 2007). These factors are consistent patterns of beliefs, attitudes, feelings, and reactions that create various outcomes among staff (Spiendler, Kruse, Zwisker, \& Pederson, 2009; Nasir, Mustaffa, Wan Shahrazad, Khairudin, \& Syed Salim, 2011).

Corresponding to the Five Factor Model, studies indicate that each of these factors has a unique influence on the behavior and feeling of individuals. In the following, these factors are well-defined obviously. Openness being one of the personality factors models refers to the individuals who are interested in new occurrences and things as well as enjoying any new experience. Individuals with a low level of openness would not attempt new experiences. The second factor of this model is conscientiousness. The conscientiousness individual prefers to pursue a specific project and most of the time the project is profitable. These individuals are reliable and self-discipline (Goldberg, 1993). The third factor of this model is the present extraversion. The individuals with this characteristic are so sociable, friendly, and energetic. The individuals that do not have this characteristic wish to work lonely and do not enjoy collaborating with others. Agreeableness assumed as the fourth factor of the Five Factor Model. The agreeableness individuals demonstrate optimistic attitudes in the direction of human nature; additionally, they are kind, friendly, and thoughtful in their personal and social life. Oppositely, individuals with low levels of this personality are unfavorable and uncooperative. The last factor of this model is neuroticism that refers to emotional instability and the degree of negative emotion (McCrea, 2010). It would be advantageous in predicting negative organizational behavior such as low job satisfaction at work. This model can predict some behaviors and reactions that appear in the work. Earlier studies such as Saklofske et al. (2007) simplified that personality factors have a noteworthy role in staff organizational behaviors. Overall, the main view of the Five Factor Model is to protect the role of personality factors on staff attitudes and opinions that can change them at various levels. This means that the amount of positive or negative feelings is motivated by these factors in the workplace.

\section{Conclusion}

According to the importance of personality on staff performance and behavior in the workplace, the role of managers, leaders, and supervisors is considerable. Because the amount of performance and responses of staff play a great role in the 
level of work outcomes; additionally, the success of work has a direct relation with staff activity and organizational behavior. In this case, recognizing and examining different types of staff personalities according to the Five Factor Model can be effective. In fact, this model described each factor comprehensively and reported staff with each of these factors showing different types of behavior and reaction.

In this regard, directors with knowledge of personality effects on staff behaviors and reactions have to organize different workshops and seminars by presenting industrial and organizational psychologists and consultants to introduce and identify these five factors to staff completely, explaining various methods to coping conflicts, and applying accurate ways. All these activities from the workplaces need additional support from the ministry of work or any type of governmental organization that focuses on staff welfare in various countries.

\section{Research suggestion}

Based on this literature review suggest that all organizations and workplaces apply at least one specific instrument to recognizing staff personality, by this survey they can obtain valuable data about staff personality and recognize how to organize and manage organizational behavior and offering suitable workshops for them. Furthermore, the researcher of current investigation recommends that in the future other researchers need to find a workable instrument or application to analyzing and discovering staff personality based on new and modern technology of the world. By this action, managers have better communicate as compare with past with their staff at the workplace.

\section{References:}

Ali, T., \& Akhter, I. (2009). Job satisfaction of faculty members in private universities in the context of Bangladesh. International Business Research, 2(4), 167-175. doi: 10.5539/ibr. v2n4p167

Althoff, R. W. (2010). The Big Five Personality Traits as Predictors of Academic Maturity. (Unpublished master's thesis). Eastern Illinois University, United State.

Ayan, S., \& Kocacik, F. (2010). The relation between the level of job satisfaction and types of personality in high school teachers. Australian Journal of Teacher Education, 35(1), 26-41. doi: 10.14221/ajte.2010v35n1.4

Barkhuizen, N., Swanepoel, S., \& Ermakova, J. (2012). Do personality factor predict job satisfaction? Alternation Special Edition, 5, 77-95.

Bauger, L. (2011). Personality, Passion, Self-esteem and Psychological Well-being among Junior Elite Athletes in Norway. (Unpublished master's thesis). University of Troms, Norway.

Clark, C. F., Kotchen, M. J., \& Moore, M. R. (2003). Internal and external influences on proenvironmental behavior: Participation in a green electricity program. Journal of Environmental Psychology, 23, 237-246. doi: 10.1016/S0272- 4944(02)00105-6

Cooper, C. A., Carpenter, D., Reiner, A., \& McCord, D. M. (2014). Personality and job satisfaction: Evidence from a sample of street-level bureaucrats. International Journal of Public Administration, 37(3), 155-162. https://doi.org/10.1080/01900692.2013.798810

Eley, D. S., Cloninger, C. R., Walters, L., Laurence, C., Synnott, R., \& Wilkinson, D. (2013). The relationship between resilience and personality traits in doctors: Implications for enhancing wellbeing. Peer J, 1, 1-16. doi:10.7717/peerj.216

Fayombo, G. (2010). The relationship between personality traits and psychological resilience among the baribbean adolescents. International Journal of Psychological Studies, 2(2), 105-116.

Furnham, A., Petrides, K. V., Jackson, C. J., \& Cotter, T. (2002). Do personality factors predict job satisfaction? Personality and Individual Differences, 33, 1325-1342. doi: 10.1016/S01918869(02)00016-8

Franzoi, S. L. (2006). Social psychology (4th ed.). America, New York: McGraw Hill 
Goldberg, L. R. (1993). The structure of phenotypic personality traits. American Psychologists, 48, 1303-1304. https://doi.org/10.1037/0003-066X.48.12.1303

Gurven, M., Rueden, C. V., Massenkoff, M., Kaplan, H., \& Lero Vie, M. (2013). How universal is the big five? Testing the five-factor model of personality variation among forager-farmers in the Bolivian Amazon. Journal of Personality and Social Psychology, 104(2), 354-370. doi: $10.1037 / \mathrm{a} 0030841$

Hazrati, E., Zabihi, R., \& Mehdizadeh, A. H. (2013). The relationship between emotional intelligence and personality features with job satisfaction status of male junior high school teachers in Islamshahr city. Journal of Educational and Management Studies, 3(3), 205-214.

Judge, T. A., Klinger, R., Simon, L. S., \& Yang, I. W. F. (2008). The contributions of personality to organizational behavior and psychology: Findings, criticisms, and future research directions. Social and Personality Psychology Compass, 2(5), 1982-2000. doi:10.1111/j.1751-9004.2008. 00136.x

Kafetsios, K., \& Zampetakis, L. A. (2008). Emotional intelligence and job satisfaction: Testing the mediatory role of positive and negative affect at work. Journal of Personality and Individual Differences, 44(3), 712-722. doi: 10.1016/j.paid.2007.10.004

Lounsbury, J. W., Hutchens, T., \& Loveland, J. M. (2005). An investigation of big five personality traits and career decidedness among early and middle adolescents. Journal of Career Assessment, 13(1), 25-39. doi:10.1177/1069072704270272

McCrae, R. R. (2010). The place of the FFM in personality psychology. Psychological Inquiry, 21(1), 57-64. doi: 10.1080/10478401003648773

Mikolajczak, M., Luminet, O., Leroy, C., \& Roy, E. (2007). Psychometric properties of the trait emotional intelligence questionnaire: Factor structure, reliability, construct, and incremental validity in a French-speaking population. Journal of Personality Assessment, 88(3), 338-353. doi: $10.1080 / 00223890701333431$

Nasir, R., Mustaffa, M. B., Wan Shahrazad, W. S., Khairudin, R., \& Syed Salim, S. S. (2011). Parental support, personality, self-efficacy as predictors for depression among medical students. Pertanika Journal Social Science and Humanities, 19(S), 9-15.

Naz, S., Rehman, S., \& Saqib, H. (2013). The relationship between job satisfaction and personality trait among bank employees. Far East Journal of Psychology and Business, 11(3), 57-72.

Petrides, K. V., Pita, R., \& Kokkinaki, F. (2007). The location of trait emotional intelligence in personality factor space. Journal of Psychology, 98, 273-289. doi: 10.1348/000712606X120618

Poropat, A. E. (2009). A meta-analysis of the five-factor model of personality and academic performance. American Psychological Association, 135(2), 322- 338. doi: 10.1037/a0014996

Reid-Cunningham, A. R. (2008). Maslow's Theory of Motivation and Hierarchy of Human Needs: A Critical Analysis. (Unpublished doctoral dissertation). University of California-Berkeley, United State.

Rothmann, S., \& Coetzer, E. P. (2003). The big five personality dimensions and job performance. Journal of Industrial Psychology, 29(1), 68-74. doi: 10.4102/sajip.v29i1.88

Saklofske, D. H., Austin, E. J., Rohr, B. A., \& Andrews, J. J. W. (2007). Personality, emotional intelligence and exercise. Journal of Health Psychology, 12(6), 937-948. doi: $10.1177 / 1359105307082458$

Spiendler, H., Kruse, C., Zwisker, A. D., \& Pederson, S. S. (2009). Increased anxiety and depression in Danish cardiac patients with typed personality: Cross validation of the typed scale (DS14). International Journal of Behavior Medicine, 16(2), 98-107. doi: 10.1007/s12529-009-9037-5.

Srivastava, S. (2010). The five-factor model describes the structure of social perceptions. Psychol Inq, 21(1), 69-75. https://doi.org/10.1080/10478401003648815

Tan, T. H., \& Waheed, A. (2011). Herzberg's motivation-hygiene theory and job satisfaction in the Malaysian retail sector: The mediating effect of love of money. Asian Academic of Management Journal, 16(1), 73-94.

Tella, A., Ayeni, C. O., \& Popoola, S. O. (2007). Work motivation, job satisfaction, and organizational commitment of library personnel in academic and research libraries in Oyo state, Nigeria. Library Philosophy and Practice, 1-16.

Voon, M. L., Lo, M. C., Ngui, K. S., \& Ayob, N. B. (2011). The influence of leadership styles on employees' job satisfaction in public sector organizations in Malaysia. International Journal of Business, Management and Social Science, 2(1), 24-32.

Wadhwa, D. S., Verghese, M., \& Wadhwa, D. S. (2011). A study on factors influencing employee job satisfaction: A study in cement industry of Chhattisgarh. International Journal of Management and Business Studies, 1(3), 109-111.

Yap, S. C. Y., Anusic, I., \& Lucas, R. E. (2012). Does personality moderate reaction and adaptation to major life events? Evidence from the British household panel survey. Journal of Research in Personality: 1-54. doi: 10.1016/j.jrp.2012.05.005

Yeop Yunus, K. N., \& Ishak, S. (2012). The relationship between internal satisfaction and external satisfaction amongst hotel customers in Malaysia. International Journal of Economics Business and Management Studies, 1(1), 21-29. 